Article

\title{
Genome-Wide Identification and Analysis of SRO Gene Family in Chinese Cabbage (Brassica rapa L.)
}

\author{
Yali Qiao ${ }^{1}$, Xueqin Gao ${ }^{1}$, Zeci Liu ${ }^{1}$, Yue $\mathrm{Wu}^{1}{ }^{1}$, Linli $\mathrm{Hu}{ }^{1,2, *}$ and Jihua $\mathrm{Yu}^{1,2, *}$ \\ 1 College of Horticulture, Gansu Agricultural University, Lanzhou 730070, China; qiaoyl@st.gsau.edu.cn (Y.Q.); \\ gaoxq@st.gsau.edu.cn (X.G.); liuzc@gsau.edu.cn (Z.L.); wuy@gsau.edu.cn (Y.W.) \\ 2 Gansu Provincial Key Laboratory of Aridland Crop Science, Gansu Agricultural University, \\ Lanzhou 730070, China \\ * Correspondence: hull@gsau.edu.cn (L.H.); yujihua@gsau.edu.cn (J.Y.); Tel.: +86-931-7632188 (J.Y.)
}

Received: 6 August 2020; Accepted: 16 September 2020; Published: 18 September 2020

\begin{abstract}
Similar to radical-induced cell death 1 (SROs) is a family of small proteins unique to plants. SRO transcription factors play an important role in plants' response to biotic and abiotic stresses. In this study, we identified $12 \mathrm{BrSRO}$ genes in Chinese cabbage (Brassica rapa L.). Among them, a comprehensive overview of the $S R O$ gene family is presented, including physical and chemical characteristics, chromosome locations, phylogenetic analysis, gene structures, motif analysis, and cis-element analyses. The number of amino acids of BrSRO genes is between 77-779 aa, isoelectric point changed from 6.02 to 9.6. Of the $12 \mathrm{BrSRO}$ genes, 11 were randomly distributed along the 7 chromosomes, while BrSRO12 was located along unassigned scaffolds. Phylogenetic analysis indicated that the SRO proteins from six species, including Arabidopsis, banana, rice, Solanum lycopersicum, Zea mays, and Chinese cabbage were divided into eleven groups. The exon-rich BrSRO6 and BrSRO12 containing 15 exons were clustered to group K. All 12 genes have motif 2, which indicate that motif 2 is a relatively conservative motif. There are many hormone and stress response elements in $\mathrm{BrSRO}$ genes. The relative expression levels of $12 \mathrm{BrSRO}$ genes under high temperature, drought, salt, and low temperature conditions were analyzed by real-time fluorescence quantitative PCR. The results indicated the relative expression level of BrSRO8 was significantly up-regulated when plants were exposed to high temperature. The relative expression levels of $\operatorname{BrSRO1}, 3,7,8$, and 9 were higher under low temperature treatment. The up-regulated genes response to drought and salt stresses were $\mathrm{BrSRO1}, 5,9$ and $\mathrm{BrSRO1}, 8$, respectively. These results indicated that these genes have certain responses to different abiotic stresses. This work has provided a foundation for further functional analyses of $S R O$ genes in Chinese cabbage.
\end{abstract}

Keywords: Chinese cabbage; SRO gene family; abiotic stress; bioinformatics; expression analysis

\section{Introduction}

When subjected to stresses, plants can survive in complex and diverse environments for stress-induced gene expression. In these processes, similar to radical-induced cell death 1 proteins (SROs) participate in multiple regulatory networks through stress response [1,2]. SRO is a family of small proteins unique to plants. It plays an important role in plant growth and development and in responding to abiotic stresses, such as salt, drought, and heavy metals. SROs generally contain a poly(ADP-ribose) polymerase catalytic (PARP, PS51059) center and a RCD1-SRO-TAF4(RST, PF12174) conservative domain [3], part of the SROs also contains N-terminal WWE (PS50918) domain [4]. In Arabidopsis, there are six members in the AtSRO family, namely AtRCD1 and AtSRO1-5 [5]. AtRCD1 is the first member of the $S R O$ family identified in Arabidopsis [6]. AtRCD1 can interact with transcription factors in the nucleus to participate in the drought response mediated by the plant abscisic acid 
signaling pathway, and can also regulate plant development through hormone signaling pathways including abscisic acid (ABA), ethylene (ETH), methyl jasmonate (MEJA) and so on [7,8]. AtSRO1 and AtRCD1, two homologous genes, have functional redundancy under different stress conditions [9]. AtSRO1 is involved in abiotic stress response, and its mutant SRO1-1 has strong resistance to osmotic and oxidative stress $[3,10]$. AtSRO5 interacts with transcription factors to regulate gene expression, and overexpression of AtSRO5 can increase the salt tolerance of transgenic plants by lowering the level of $\mathrm{H}_{2} \mathrm{O}_{2}$ in the roots [11]. AtSRO2 and AtSRO3 can respond to strong light, salt, and ozone stress; AtSRO4 has no clear function reported [12]. SROs have also been partially studied in apple, rice, wheat, corn, continental cotton, tomato, and other crops. For example, in apple, $M d R C D 1$ can regulate the pore size through ABA signaling pathway, tolerate drought stress, and regulate root growth [13]. In rice, OsSRO1c participates in drought and oxidative stress through promoting stomatal closure and $\mathrm{H}_{2} \mathrm{O}_{2}$ accumulation by regulating SNAC1 and DST [14]. In wheat, Ta-SRO1 can improve drought tolerance by regulating REDOX balance in plants [1]. The $S R O$ gene families in various species have been identified, and the mechanism of $S R O s$ in response to drought stress is becoming increasingly clear.

Although a large number of studies on SRO genes in various species have been conducted, studies on SRO genes of Chinese cabbage have still not been reported. Chinese cabbage (Brassica rapa L.), which originated from China, is one of the specialty vegetables in the country. Chinese cabbage is rich in a variety of nutrients and is loved by consumers. Leaf bulb is the main edible part of Chinese cabbage. The growth and development of each organ of Chinese cabbage directly affect the development of leaf bulb, and then affect the yield and quality of Chinese cabbage. The development of Chinese cabbage is controlled by both gene and environment. The completion of genome sequencing of Chinese cabbage in 2011 [15] provided important reference information for bioinformatics analysis, genetic breeding, and key functional gene mining of Chinese cabbage gene family system at the whole genome level.

At present, multiple gene families of Chinese cabbage such as HSF [16], AQP [17], TCP [18], and $M Y B$ [19] have been identified by bioinformatics methods, and some genes have also been functionally verified. However, the identification and expression pattern response to various stresses of $S R O$ gene families in Chinese cabbage have not been reported until now. Therefore, in this study, based on whole genome sequencing results, the members of SRO gene family in Chinese cabbage were identified via a bioinformatics analysis method, and subsequently the physical and chemical properties, evolutionary characteristics of its members, and protein structure were analyzed. Finally, the expression pattern of $B r S R O s^{\prime}$ response to high temperature, low temperature, drought, and salt stress were set up via real-time quantification PCR methods. Our study provides a foundation for further research on the molecular mechanism of SRO gene mediating physiological growth process and stress response, and a significant basis for the genetic improvement of Chinese cabbage.

\section{Result}

\subsection{Identification and Chromosomal Location of the SRO Family Genes in Chinese Cabbage}

In this study, a total of $12 \mathrm{BrSRO}$ genes were identified in the genome network of Chinese cabbage (Table 1). All genes were named respectively from BrSRO1 to BrSRO12 according to their position from the top to the bottom of Chinese cabbage chromosomes A02-A09. The number of amino acids of BrSRO genes is between 77-779 aa, with BrSRO12 encoding the longest protein and highest molecular weight $(85,523.47)$ and BrSRO1 encoding the shortest protein and lowest molecular weight $(8830.55)$. Furthermore, the isoelectric point changed from 6.02 (BrSRO10) to 9.6 (BrSRO1) and instability index changed from 33.9 (BrSRO1) to 59.1 (BrSRO2). BrSRO1 has the largest fat index (100.13); the fat indexes of the rest $B r S R O$ genes are between 61.69 and 88.16. In addition, the protein subcellular localization prediction showed that $\mathrm{BrSRO1}$ and $\mathrm{BraSRO9}$ proteins were predictably located in the chloroplast and nucleus. BrSRO2, BrSRO4, BrSRO7, and BrSRO11 were predictably located in the chloroplast. The remaining genes were predicted to be located in the nucleus. 
Table 1. Physiochemical characteristics of identified BrSRO genes.

\begin{tabular}{|c|c|c|c|c|c|c|c|c|c|}
\hline $\begin{array}{l}\text { Gene } \\
\text { Name }\end{array}$ & Gene ID & $\begin{array}{c}\text { Chromosome } \\
\text { Location }\end{array}$ & $\begin{array}{c}\text { Protein } \\
\text { Length (aa) }\end{array}$ & $\begin{array}{c}\text { Molecular } \\
\text { Weight } \\
\text { (kd) }\end{array}$ & PI & $\begin{array}{c}\text { Total } \\
\text { Number of } \\
\text { Atoms }\end{array}$ & $\begin{array}{l}\text { INSTABILITY } \\
\text { Index }\end{array}$ & $\begin{array}{c}\text { Fat } \\
\text { Index }\end{array}$ & $\begin{array}{c}\text { Predicted } \\
\text { Subcellular } \\
\text { Localization }\end{array}$ \\
\hline BrSRO1 & Bra033139 & $\begin{array}{c}\text { Chromosome A02: } \\
16,846,412-16,846,733\end{array}$ & 77 & 8830.55 & 9.6 & 1272 & 33.9 & 100.13 & $\begin{array}{l}\text { Chloroplast. } \\
\text { Nucleus. }\end{array}$ \\
\hline $\mathrm{BrSRO} 2$ & Bra029254 & $\begin{array}{c}\text { Chromosome A02: } \\
26,296,663-26,297,969\end{array}$ & 303 & $34,150.08$ & 8.68 & 4793 & 59.1 & 82.71 & Chloroplast. \\
\hline $\mathrm{BrSRO} 3$ & Bra017317 & $\begin{array}{l}\text { Chromosome A04: } \\
15,393,395-15,395,430\end{array}$ & 530 & $58,637.64$ & 6.99 & 8192 & 34.19 & 80.55 & Nucleus. \\
\hline $\mathrm{BrSRO} 4$ & Bra005336 & $\begin{array}{l}\text { Chromosome A05: } \\
4,905,877-4,908,322\end{array}$ & 524 & $58,577.61$ & 6.1 & 8178 & 37.71 & 80.29 & Chloroplast. \\
\hline BrSRO5 & Bra010096 & $\begin{array}{l}\text { Chromosome A06: } \\
19,383,958-19,385,124\end{array}$ & 313 & $34,876.77$ & 8.59 & 4889 & 57.49 & 80 & Nucleus. \\
\hline BrSRO6 & Bra033662 & $\begin{array}{l}\text { Chromosome A06: } \\
25,753,358-25,757,833\end{array}$ & 771 & $85,056.17$ & 9.07 & 11,856 & 57.48 & 63.97 & Nucleus. \\
\hline BrSRO7 & Bra012380 & $\begin{array}{l}\text { Chromosome A07: } \\
8,098,261-8,099,752\end{array}$ & 310 & $34,575.22$ & 8.86 & 4865 & 45.5 & 85.29 & Chloroplast. \\
\hline BrSRO8 & Bra016219 & $\begin{array}{l}\text { Chromosome A07: } \\
18,821,147-18,822,313\end{array}$ & 304 & $33,789.47$ & 8.15 & 4744 & 39 & 88.16 & Chloroplast. \\
\hline BrSRO9 & Bra035511 & $\begin{array}{l}\text { Chromosome A08: } \\
7,983,100-7,985,345\end{array}$ & 558 & $62,697.49$ & 6.59 & 8754 & 37.36 & 79 & $\begin{array}{l}\text { Chloroplast. } \\
\text { Nucleus. }\end{array}$ \\
\hline BrSRO10 & Bra023252 & $\begin{array}{l}\text { Chromosome A09: } \\
20,223,502-20,225,770\end{array}$ & 482 & $54,230.68$ & 6.02 & 7557 & 42.34 & 78.28 & Nucleus. \\
\hline BrSRO11 & Bra024609 & $\begin{array}{l}\text { Chromosome A09: } \\
24,077,869-24,079,029\end{array}$ & 308 & $33,418.73$ & 6.19 & 4682 & 40.86 & 84.84 & Chloroplast. \\
\hline BrSRO12 & Bra035961 & $\begin{array}{l}\text { Scaffold000111: } \\
11,933-15,826\end{array}$ & 779 & $85,523.47$ & 8.98 & 11,902 & 55.21 & 61.69 & Nucleus. \\
\hline
\end{tabular}

The identified 12 SRO genes in Chinese cabbage were mapped onto chromosomes or scaffolds. Among these, 11 genes (BrSRO1-11) were located in chromosomes, whereas the BrSRO12 were distributed in unmapped scaffolds (Figure 1). In detail, the 11 predicted $B r S R O s$ were distributed unevenly across its 7 chromosomes. Each of chromosomes A02, 06, 07, and 09 harbored two BrSRO genes, and a single BrSRO gene was located in each of the chromosomes A04, 05, and 08.

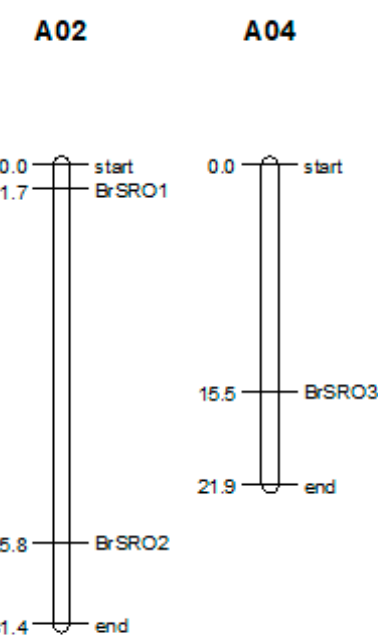

A05

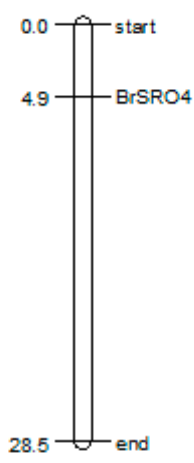

A06

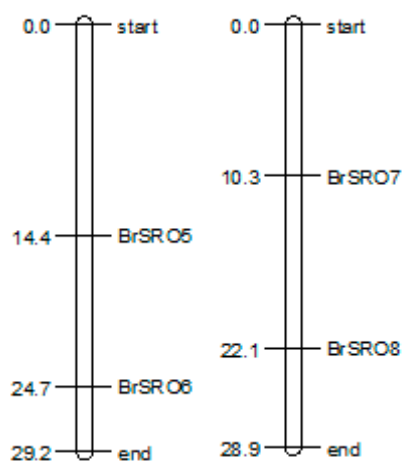

A08

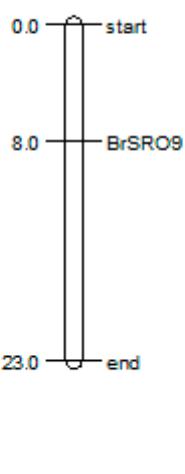

A09

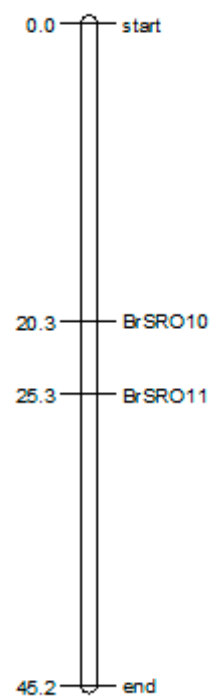

Figure 1. The chromosomal mapping analysis of the $S R O$ gene family in Chinese cabbage. The chromosome number (A02-A09) is indicated at the top of each chromosome. The numbers on the left of each chromosome represent the initial position of each gene. 


\subsection{Phylogenetic Analysis of the SRO Family Genes in Chinese Cabbage}

The SRO proteins in Chinese cabbage were compared with other species to investigate the evolutionary relationships of SRO proteins. A phylogenetic tree was constructed on the basis of 40 putative nonredundant SRO protein sequences from six species, including Arabidopsis, banana, rice, Solanum lycopersicum, Zea mays and Chinese cabbage (Figure 2). All 40 SRO proteins were clustered into eleven groups (A-K), which consisted 6, 2, 1, 5, 4, 2, 2, 5, 5, 5, and 2 members, respectively. All BrSROs were clustered into Group A, H, I, and K, which indicated that the SRO of Chinese cabbage gene has higher homology with the Arabidopsis and tomato genes, compared with rice, maize and banana. The low bootstrap values in the tree are due to divergent SRO protein sequence among Arabidopsis, banana, rice, Solanum lycopersicum, Zea mays, and Chinese cabbage. This is not surprising, given that both $A$. thaliana and B. rapa belong to cruciferous plants, and the SRO genes in these two species were clustered together.

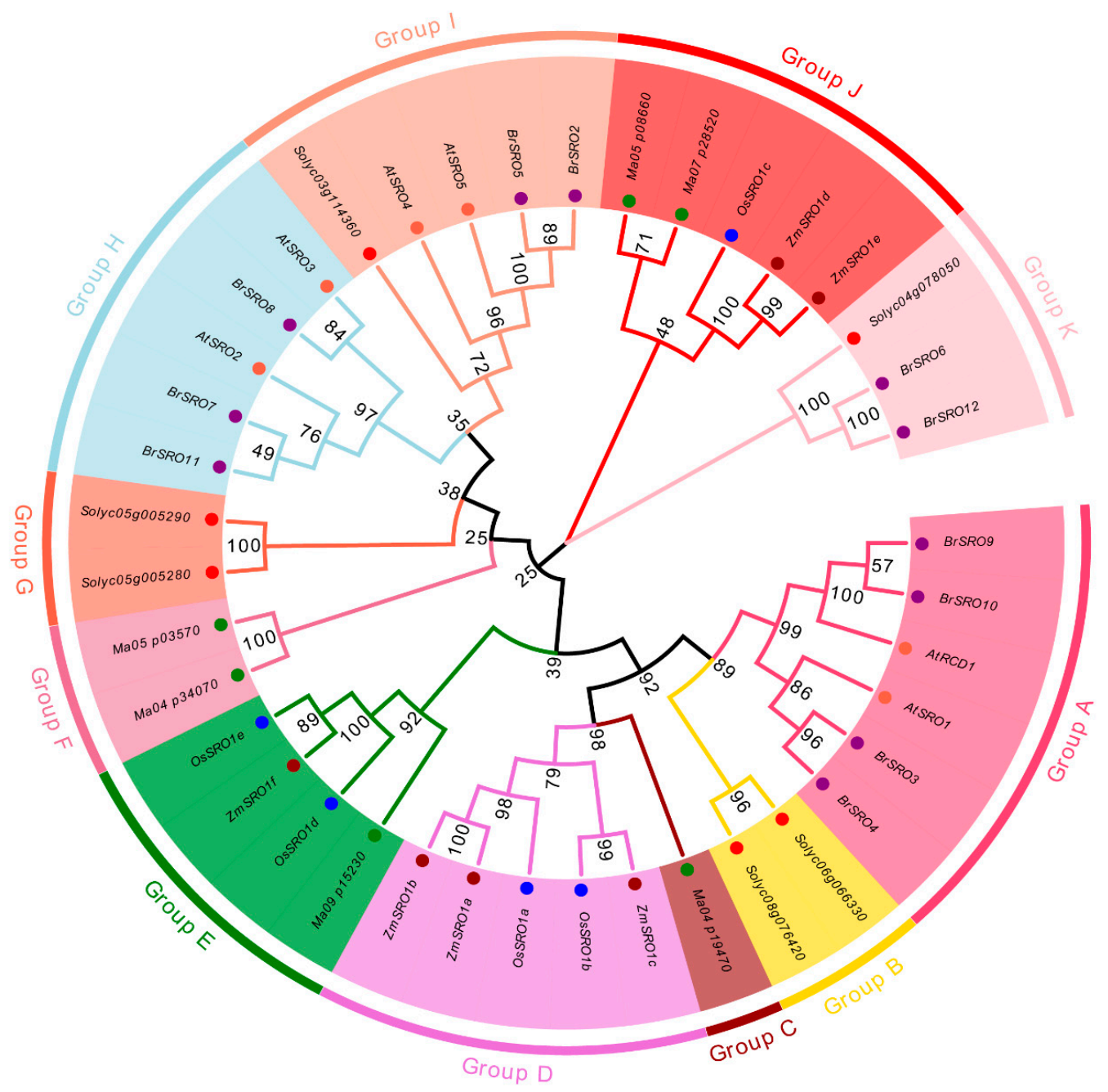

Figure 2. Phylogenetic tree of the similar to radical-induced cell death 1 (SRO) genes from Arabidopsis thaliana (At), Solanum Lycopersicum (Sl), Brassica rapa (Br), O. sativa (Os), Zea mays (Zm), Musa acuminate (Ma). In total, 6 AtSROs, 6 SISROs, 11 BrSROs, 5 OsSROs, 6 ZmSROs, and 5 MaSROs were included. The phylogenetic tree was constructed for the SRO protein sequences in Arabidopsis thaliana (tomato), Solanum Lycopersicum (red), Brassica rapa (purple), Oryza sativa (blue), Zea mays (darkred) and Musa acuminate (green) using the Maximum-Likelihood method in MEGA 7.0. Bootstrap values from 1000 replicates are displayed at each node. The proteins on the tree can be divided into 11 groups from Group A to Group K, and the different groups are indicated by different colors. 


\subsection{Gene Structure of the BrSRO Genes}

The predicted exon-intron structure was analyzed to gain an insight into the variation of the $S R O$ genes in Chinese cabbage. On the basis of the evolutionary relationships of the Chinese cabbage phylogenetic tree (Figure 3a), the structure features were determined (Figure 3b). Phylogenetic analysis indicated that $12 \mathrm{BrSRO}$ family members were divided into four groups (A, H, I, and $\mathrm{K}$ ). All of the $12 \mathrm{BrSRO}$ genes have complete gene structure. Interestingly, the exon-rich $\mathrm{BrSRO}$ genes containing 15 exons were clustered in group $\mathrm{K}$, while the number of exons in the rest of groups ranged from 2 to 5 , and the exon number of BrSRO1 was the lowest.

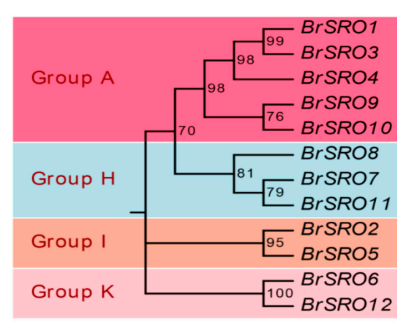

a

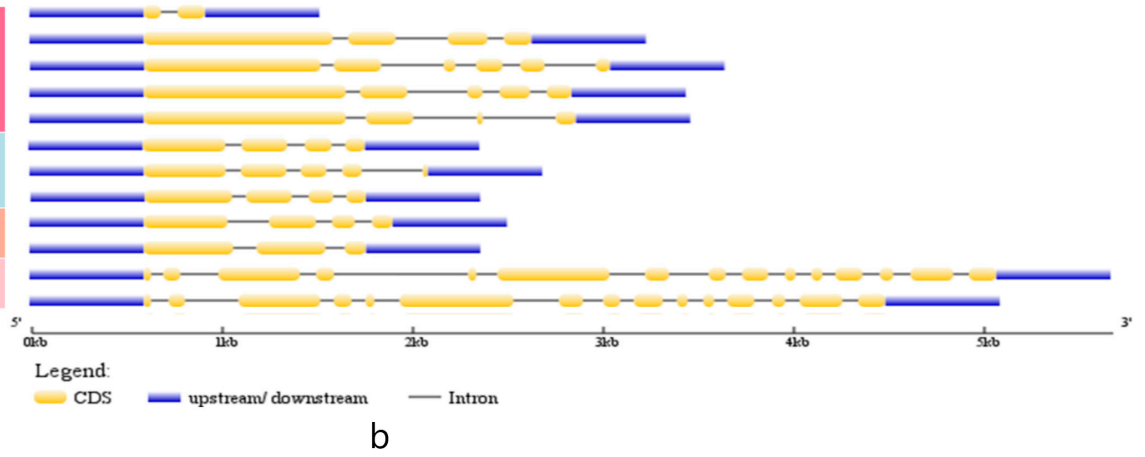

b

Figure 3. Compositions of introns and exons of BrSRO genes based on the phylogenetic relations. The amino acid sequences of the SRO proteins were aligned with ClustalX, and the phylogenetic tree was constructed using the neighbor joining method in MEGA 7.0 software (a). Each node is represented by a number that indicates the bootstrap value for 1000 replicates. The right side illustrates the exon-intron organization of the corresponding SRO genes. The exon and intron are represented by the yellow boxes and black lines, respectively. The scale bar represents $1 \mathrm{~kb}(\mathbf{b})$. The blue boxes represented upstream/downstream.

\subsection{Conserved Motifs Analysis of BrSRO Proteins}

The phylogenetic relationship and classification of BrSROs were further supported by motif analysis (Figure 4). Ten (10) conserved motifs of BrSROs were captured by motif analysis using MEME suite. All genes have the motifs (motif 1, 2, 3, 4, 5, 6, 7, and 9) in A group except for BrSRO1. The genes of the $\mathrm{H}$ group (BrSRO7, BrSRO8, and BrSRO11) have the same motifs, which are motif 1, 2, 4, 6, and 8 . In addition, the genes in group I (BrSRO2 and BrSRO5) have the same motifs, which are motif 1, 2, 4, and 8 . There are only three motifs (motif 2, 9, and 10) in Group K. Interestingly, all 12 genes have motif 2 , which indicates that motif 2 is relatively conservative. 
a

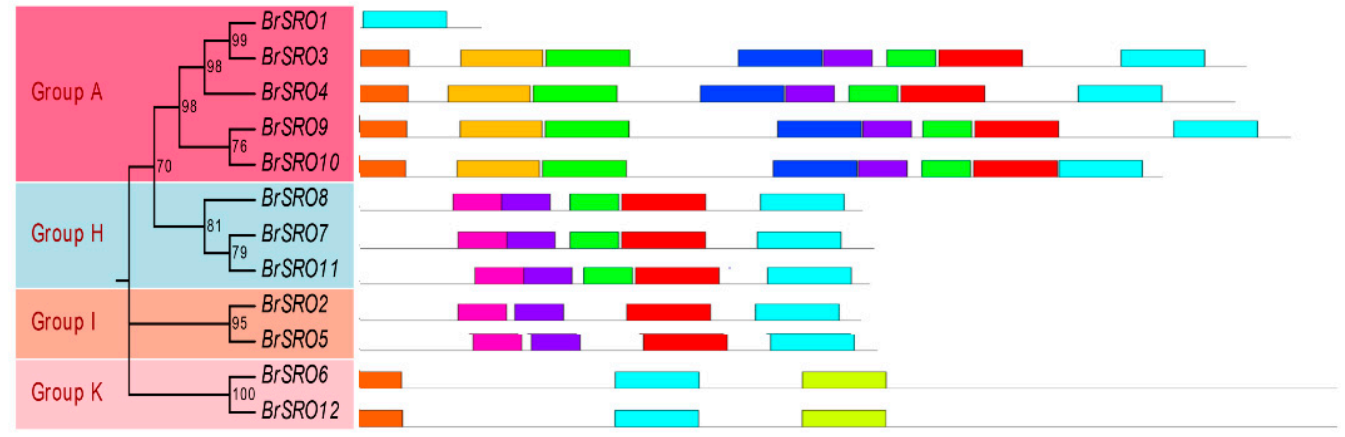

b

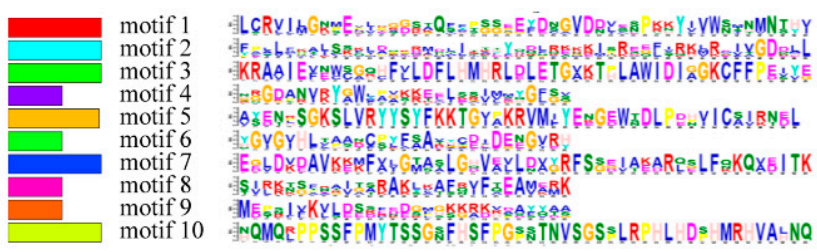

Figure 4. The conserved motifs of the BrSRO proteins based on the phylogenetic relationship. The BrSRO proteins phylogenetic relationship (a). The BrSRO proteins annotated with the MEME server (b). Distribution of the BrSRO conserved motifs in Chinese cabbage was analyzed by the online tool MEME. Ten motifs are marked by different colors.

\subsection{Cis-Elements in the Promoters of BrSRO Genes}

In order to study the response of $B r S R O$ gene to various signal factors, we searched $2 \mathrm{~kb}$ sequences upstream of the start codon of BrSROs family for elements related to stress response. There are many light signal elements (MRE, box-4, TCT motif, etc.), hormone and stress response elements. The cis-acting elements related to hormones and stress response in $B r S R O$ gene promoter were analyzed and illustrated. It can be seen from the table that $B r S R O$ gene promoter contains 12 cis-elements that respond to hormones and stress. Interestingly, $12 \mathrm{BrSRO}$ genes include at least one of the 12 predicted types of cis-elements in their promoter regions (Table 2). $10 \mathrm{BrSRO}$ genes contain the ABRE cis-element; only two genes (BrSRO1 and BrSRO9) lack it. There are more MeJA response elements (CGTCA-motif, TGACG-motif) in the BrSRO genes than other cis-elements. MBS is located in BrSRO1, 3, 4, 7, 8, 11, and 12. All genes except $B r S R O 1,4,5,8$, and 10 have TATC-motif/P-box, indicating they are related to GA response. Only BrSRO3, 4, 5, and 7 have LTR and only two genes, namely, BrSRO2 and BrSRO8, contain the TC-rich repeats cis-element in their promoter regions. These results suggest that SRO family may play a crucial role in the growth and development of Chinese cabbage, as well as in various hormones and stress. 
Table 2. Putative cis-elements existed in the $2 \mathrm{~kb}$ upstream region of $B r S R O$ gene family.

\begin{tabular}{|c|c|c|c|c|c|c|c|c|c|c|c|c|}
\hline \multirow{3}{*}{ Gene } & \multicolumn{8}{|c|}{ Hormonal Response Cis-Elements } & \multicolumn{4}{|c|}{ Stress Response Cis-Elements } \\
\hline & \multirow{2}{*}{$\begin{array}{c}\begin{array}{c}\text { Abscisic Acid } \\
\text { Response } \\
\text { Element }\end{array} \\
\text { ABRE }\end{array}$} & \multicolumn{2}{|c|}{$\begin{array}{l}\text { Methyl Jasmonate } \\
\text { Response Element }\end{array}$} & \multirow{2}{*}{\begin{tabular}{|c|}
$\begin{array}{c}\text { Salicylic Acid } \\
\text { Response } \\
\text { Element }\end{array}$ \\
TCA-Element
\end{tabular}} & \multirow{2}{*}{$\begin{array}{c}\begin{array}{c}\text { Auxin } \\
\text { Response } \\
\text { Element }\end{array} \\
\text { TGA-Element }\end{array}$} & \multicolumn{3}{|c|}{ Gibberellin Response Element } & \multirow{2}{*}{$\begin{array}{c}\begin{array}{c}\text { Anaerobic } \\
\text { Induction } \\
\text { Response Element }\end{array} \\
\text { ARE }\end{array}$} & \multirow{2}{*}{$\begin{array}{c}\begin{array}{c}\text { Drought } \\
\text { Response } \\
\text { Element }\end{array} \\
\text { MBS } \\
\end{array}$} & \multirow{2}{*}{$\begin{array}{c}\begin{array}{c}\text { Low-Temperature } \\
\text { Response Element }\end{array} \\
\text { LTR }\end{array}$} & \multirow{2}{*}{$\begin{array}{c}\text { Defense and } \\
\text { Stress Response } \\
\text { Element }\end{array}$} \\
\hline & & CGTCA-Motif & TGACG-Motif & & & GARE-Motif & TATC-Box & P-Box & & & & \\
\hline BrSRO1 & 0 & 3 & 3 & 0 & 0 & 1 & 0 & 0 & 2 & 3 & 0 & 0 \\
\hline $\mathrm{BrSRO} 2$ & 4 & 2 & 2 & 0 & 3 & 0 & 2 & 1 & 3 & 0 & 0 & 1 \\
\hline $\mathrm{BrSRO} 3$ & 1 & 0 & 0 & 0 & 0 & 0 & 1 & 1 & 4 & 4 & 1 & 0 \\
\hline $\mathrm{BrSRO} 4$ & 5 & 0 & 0 & 1 & 2 & 0 & 0 & 0 & 4 & 1 & 1 & 0 \\
\hline BrSRO5 & 5 & 0 & 0 & 0 & 2 & 0 & 0 & 0 & 0 & 1 & 1 & 0 \\
\hline BrSRO6 & 1 & 2 & 2 & 0 & 2 & 0 & 0 & 0 & 5 & 0 & 0 & 0 \\
\hline $\mathrm{BrSRO} 7$ & 2 & 0 & 0 & 0 & 1 & 0 & 0 & 1 & 1 & 1 & 1 & 0 \\
\hline BrSRO8 & 3 & 5 & 2 & 0 & 0 & 0 & 0 & 0 & 2 & 1 & 0 & 1 \\
\hline BrSRO9 & 0 & 3 & 3 & 0 & 1 & 1 & 0 & 0 & 4 & 2 & 0 & 0 \\
\hline BrSRO10 & 1 & 4 & 5 & 1 & 1 & 1 & 0 & 3 & 0 & 0 & 1 & 0 \\
\hline BrSRO11 & 3 & 3 & 3 & 0 & 0 & 0 & 0 & 1 & 0 & 0 & 0 & 0 \\
\hline BrSRO12 & 5 & 4 & 4 & 1 & 1 & 0 & 0 & 2 & 0 & 2 & 0 & 0 \\
\hline
\end{tabular}




\subsection{Relative Expression of 12 BrSRO Genes}

Using qRT-PCR, the relative expression levels of $B r S R O$ genes in leaf were analyzed under abiotic stresses for $24 \mathrm{~h}, 48 \mathrm{~h}$, and $72 \mathrm{~h}$. The results showed that the expression of BrSROs responded differently to various abiotic stresses. Under high temperature stress, the relative expression levels of $\mathrm{BrSRO1}, 5,6$, and 8 genes were up-regulated and the rest of genes was down-regulated at $24 \mathrm{~h}$. The relative expression levels of $\mathrm{BrSRO1}, 8$, and 9 genes were up-regulated and $\mathrm{BrSRO} 4$ and $\mathrm{BrSRO} 5$ were down-regulated at $48 \mathrm{~h}$, while $\mathrm{BrSRO}$, 5 and $\mathrm{BrSRO} 8$ were up-regulated at $72 \mathrm{~h}$. Interestingly, the relative expression level of $\mathrm{BrSRO} 8$ was significantly up-regulated at three time points and reached the highest level at $24 \mathrm{~h}$ (Figure 5). Under low temperature, the relative expression levels of $\mathrm{BrSRO1}, 3,7,8,9$, and 12 genes were up-regulated at three time points and the up-regulated amplitudes of different genes were different at different time points (Figure 5). Under drought stress, the relative expression levels of $\mathrm{BrSRO1}, 5$, and 9 genes were up-regulated at three points and the relative expression level of BrSRO5 reached the highest level at $72 \mathrm{~h}$ while BrSRO9 reached the highest level at $24 \mathrm{~h}$ and $48 \mathrm{~h}$ (Figure 5). Under $2 \% \mathrm{NaCl}$ treatment, the relative expression level of all the $\mathrm{BrSRO}$ genes were up-regulated at $24 \mathrm{~h}$, moreover, $\mathrm{BrSRO} 5$ and $\mathrm{BrSRO} 8$ were significantly up-regulated and about 7.5 times the control. At $48 \mathrm{~h}$, the $\operatorname{BrSRO1}, 3,7,8,9$, and 11 were up-regulated while $B r S R O 2,3,4$, and 5 were reached lowest for $48 \mathrm{~h}$. Only BrSRO1, 8 and 12 up-regulated at $24 \mathrm{~h}, 48 \mathrm{~h}$, and $72 \mathrm{~h}$ (Figure 5). Thus, it could be seen that the up-regulation of $\mathrm{BrSRO1}$ and 8 genes were significant under all treatments, while the up-regulation of BrSRO9 was significant under drought, low temperature, and salt stresses. The expression of BrSRO12 was not significantly up-regulated or down-regulated in all treatments compared with the control. BrSRO5 gene was significantly up-regulated under drought and salt treatments, and $B r S R O 7$ gene was significantly up-regulated under drought and low-temperature treatments. The above candidate genes (BrSRO1, 5, 7, 8, and 9) were used for functional analyses in the succeeding experiment.
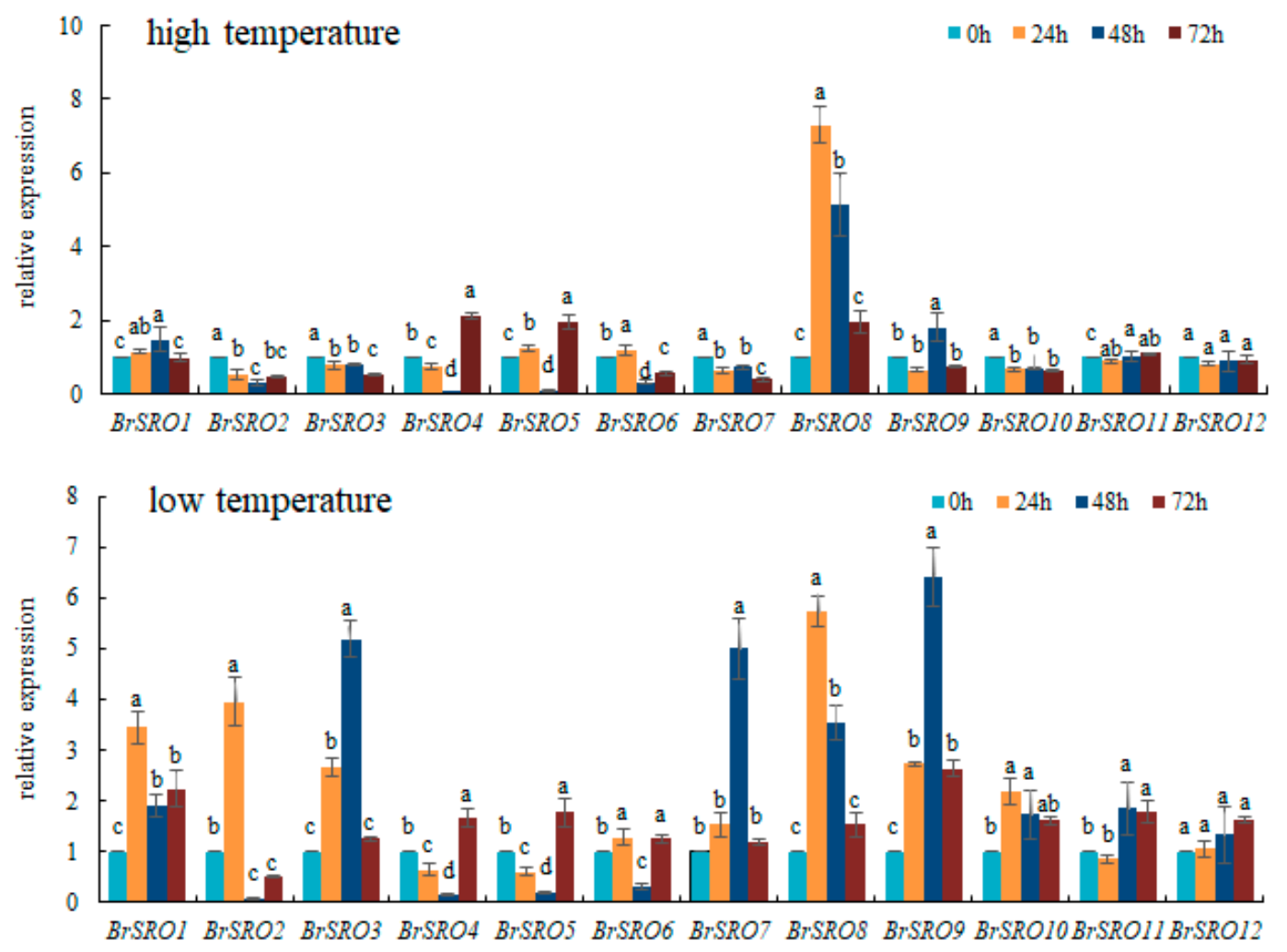

Figure 5. Cont. 

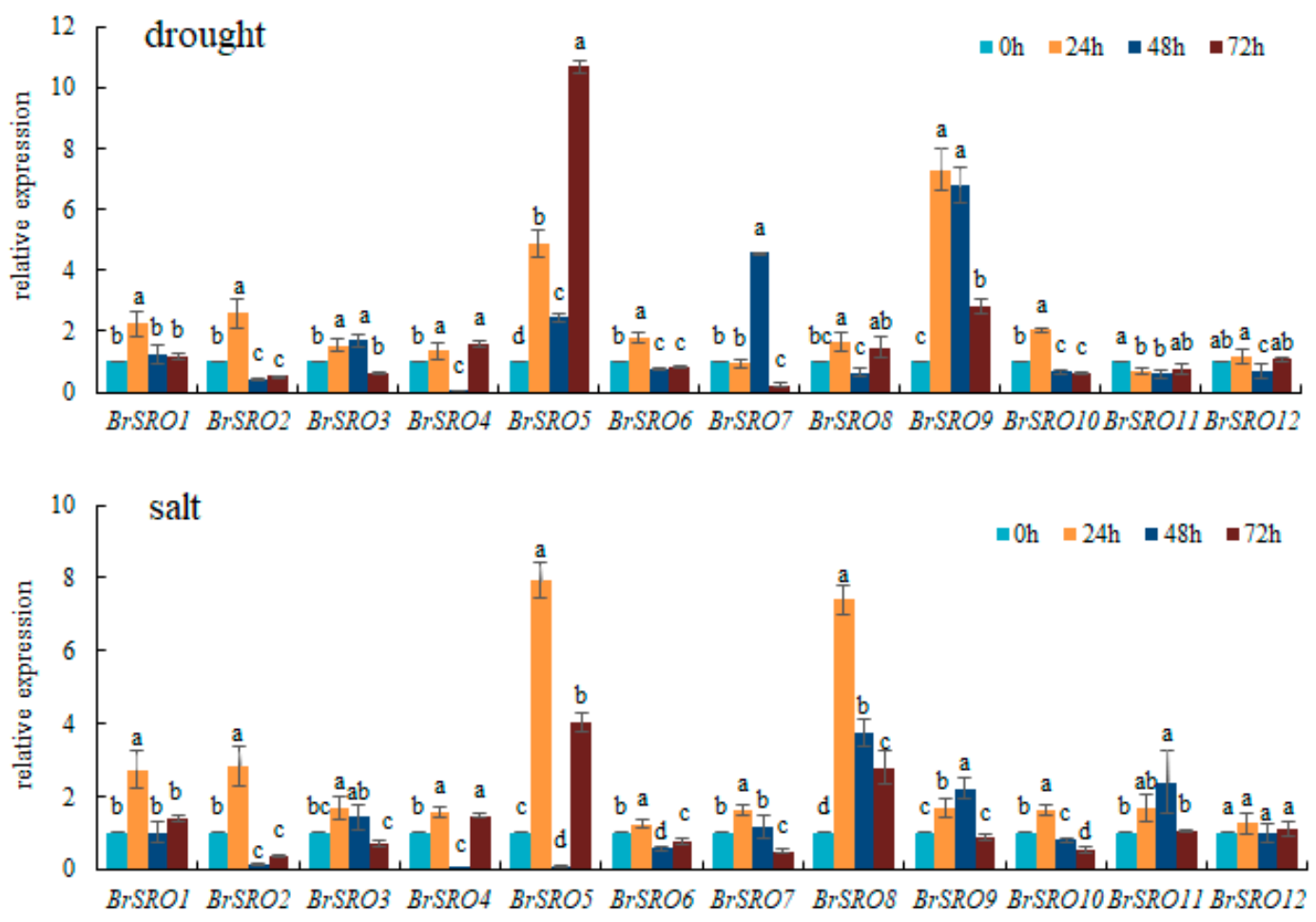

Figure 5. Expression profiles of $12 \mathrm{BrSRO}$ genes in response to high temperature treatment, low-temperature treatment, drought treatment, and salt treatment. Quantitative reverse transcription polymerase chain reaction (qRT-PCR) analyses were used to assess the transcript levels of BrSROs in leaves sampled at $24 \mathrm{~h}, 48 \mathrm{~h}$ and $72 \mathrm{~h}$ after high temperature, low-temperature treatment, drought, and salt treatment in Chinese cabbage seedlings. $0 \mathrm{~h}$ as control. Three sets of repeats are set for each process. Error bars indicate standard deviations of three replicates and different letters describe significant differences at $p \leq 0.05$ level among different time points within the same gene.

\section{Discussion}

The SRO protein family is highly conserved and found in all land plant species [5]. Several SROs have been identified as involved in plant development and stresses response. However, the family members and functions of SROs are largely unknown in Chinese cabbage. The exact biochemical functions of the SRO proteins remain unknown. The SROs are characterized by the plant-specific domain architecture which contains a poly(ADP-ribose) polymerase catalytic (PARP, PF00644) and a C-terminal RCD1-SRO-TAF4 (RST, PF12174) domain [5]. In addition to these two domains, some SRO proteins have an N-terminal WWE domain (PF02825). The RST domain is plant-specific and present in SROs and TAF4 proteins. Previous studies have demonstrated that PARP-RST domains are specific to plants, while WWE-PARP domains are widely conserved in organisms even as distantly related as humans $[20,21]$. The RST domain is essential for the interaction between RCD1 and other TFs [3]. PARPs are a class of enzymes that are involved in many biological processes, including DNA damage repair, transcription, cell death pathways, and chromatin modification/remodeling [22]. In this study, a total of $12 \mathrm{BrSROs}$ genes were identified from the Chinese cabbage genome and named BrSRO1-BrSRO12, according to chromosome location. Only two genes, BrSRO4 and BrSRO9, were identified as having the WWE domain, whereas the rest of BrSROs only have the RST domain and PARP domain, lacking WWE domain. From the analysis of physicochemical properties of protein, the number and molecular weight of amino acids are quite different between BrSRO1 and BrSRO12, which indicates that there are some differences in their structure and function. Phylogenetic tree analysis showed that SRO proteins of Chinese cabbage and Arabidopsis thaliana were highly similar, and their genetic relationships were also similar, and we can infer that there is functional similarity. The study of exons and introns is helpful to understand the differences of gene structure and function [23]. 
The number of BrSRO exons in the same group was very close, so most genes showed conservative gene structure, which supported a close evolutionary relationship [23]. Interestingly, the K group was located in the exon-rich region. It was proposed that the rates of intron creation are higher during earlier periods of plant evolution [24]. Additionally, the rate of intron loss is greater than the rate of intron gain after segmental duplication. Thus, it is possible that the group $\mathrm{K}$ may represent the original genes of SRO family [24]. Motif analysis further demonstrated the structural similarity of A, H, I, and K groups. All genes have motif 2, indicating that RST domain exists in motif 2. All genes contain cis-acting elements of light response. There are more gibberellin response elements, and methyl jasmonate response elements. Methyl jasmonate elements are important phytohormones that mediate plant development and defense mechanisms against biotic (i.e., necrotrophic pathogen infection and herbivorous insect attack) and abiotic (i.e., mechanical wounding) stress [25]. Methyl jasmonate can also be used as the core signal factor of plant resistance to insect invasion [26]. Salicylic acid (SA) is an important signaling molecule for plants to cope with biotic or abiotic stress [12]. Gibberellins are phytohormones that regulate multiple developmental processes, such as seed germination, stem elongation, flowering, and fruit development [27]. Many cis elements related to abscisic acid and drought stress response were found in the promoter region of BrSRO gene, which indicated that BrSRO gene family might respond to drought stress through the hormone signal transduction pathway.

The SRO family not only affects plants growth and development, but also affects their response to various stresses. The SRO family has proven to be able to respond to abiotic stress in many plants. For example, the relative expression level of OsSRO1c was significantly up-regulated under ABA and JA treatments. Ta-SRO1 can regulate the oxygen content in wheat. Chemical reduction balance was used to improve the tolerance to drought, high salt, and $\mathrm{H}_{2} \mathrm{O}_{2}$ stress [1]. The expression level of MdSRO4 in apples treated with $100 \mu \mathrm{mol} \mathrm{L}{ }^{-1} \mathrm{ABA}$ and $4{ }^{\circ} \mathrm{C}$ were 14 and 37 times higher than that of ABA and $4{ }^{\circ} \mathrm{C}$, respectively. Under $20 \%$ polyethylene glycol (PEG) treatment, the relative expression levels of MdRCD1, MdSRO2, and MdSRO3 were up-regulated by 18, 17, and 14 times compared with that of MdSRO4, respectively, indicating that MdSRO4 could respond to ABA and chilling stress, $M d R C D 1, M d S R O 2$, and MdSRO3 could respond to drought stress [13]. In this study, the expression levels of $B r S R O$ genes in leaves were analyzed under abiotic stresses for $24 \mathrm{~h}, 48 \mathrm{~h}$, and $72 \mathrm{~h}$. Our results showed that the responses of BrSROs were different among heat, low temperature, drought, and salt stresses. BrSRO8 is sensitive to high temperature, and the expression of BrSRO1, 3, 7, 8, and 9 was higher under low temperature treatment. The response to drought stress was BrSRO1, 5, and 9, and to $\mathrm{NaCl}$ stress was BrSRO7 and BrSRO8. The expression level changed with the time of treatment; it may be that plants regulate themselves to resist changes in the external environment. Interestingly, the expression levels of all 12 genes were up-regulated after $24 \mathrm{~h}$ salt treatment, indicating all the genes responded to salt stress at $24 \mathrm{~h}$. Excess salts in soils cause growth arrest, molecular damage, and even the death of many of the salt-sensitive crop species that are grown today [28,29]. Thus it can be predicted that the BrSRO genes family may play an important role in the resistance to salt stress. Two SRO genes, GHSRO04 (Gen bank accession number kr534896) and GHSRO08 (Gen bank accession number kr534895) have been cloned from upland cotton. The two genes were induced to express by high salt and drought, indicating that SRO plays an important role in regulating the growth and development of cotton under pathogen attack, salt, and drought stresses, and has potential utilization value for the genetic improvement of cotton germplasm [30]. Whether the function of SRO genes in Chinese cabbage work under biotic and abiotic stresses or not, the candidate genes with higher expression levels (BrSRO1, 5, 7, 8, and 9) at three time points under abiotic stresses were selected to further verify their functions in the future. 


\section{Materials and Methods}

\subsection{Identification and Sequence Analysis of SRO Genes in Chinese Cabbage}

Six known ID of Arabidopsis thaliana SRO genes [12] were put into Arabidopsis genome database (TAIR) [31] to obtain their protein sequences. Using Arabidopsis SRO protein sequences as probes, the candidate members of Chinese cabbage SRO family were searched and the coding sequences (CDS) and amino acid sequences of the B. rapa SRO genes were downloaded from the Brassica database [32]. The banana SRO genes and protein sequences were downloaded from the Banana Genome Hub [33], the rice SRO genes and protein sequences from the Rice Genome Annotation Project [34], and the website of Phytozome [35] was used to search for the SROs from Solanum lycopersicum and Zea mays. The candidate sequences with conservative domains of PARP (PS51059) and RST (PF12174) were then inspected using the SMART program [36]. Subsequently, the Prot-Param tool [37] was used to analyze the physicochemical parameters (i.e., length, molecular weight, and isoelectric point) of the SRO proteins. Subcellular localization prediction was carried out with the Plant-mPLoc [38].

\subsection{Phylogenetic Analysis of SRO Genes in Chinese Cabbage}

The phylogenetic tree was constructed with MEGA 7.0 (https://www.megasoftware.net/home) [39] on the basis of alignment with the amino acid sequences of the BrSRO proteins using the neighbor-joining method [40] with 1000 bootstrap replicates [41].

\subsection{Gene Structure and Conserved Motifs Analysis of BrSROs}

The distribution of the conserved motifs based on amino acid sequence was conducted with the online MEME program [42] and the MEME search was carried out with the following parameters: maximum number of motifs set at 10, a minimum width of 6 and a maximum width of 50 . The other parameters were set as default. The exon-intron structure of each $B r S R O$ was determined by aligning the full-length cDNA sequence with the genomic DNA sequence. The schematic structure of each $B r S R O$ was constructed using the Gene Structure Display Server (GSDS 2.0) (http://gsds.cbi.pku.edu.cn) [43].

\subsection{Chromosomal Distribution and Cis-Element Analyses of SRO Genes in Chinese Cabbage}

The information about chromosomal distribution was obtained from the Chinese cabbage genome database [32], and the chromosomal location of BrSRO genes was illustrated from top to bottom concerning their position in the genome annotation using Mapchart [44]. For identification of cis-elements located at the promoter regions of SRO genes, the 2000 bp genomic DNA sequences upstream before the initiation codon (ATG) of each BrSRO gene were downloaded from the Chinese cabbage genome database. The PlantCARE database [45] was utilized to search the cis-regulatory elements in promoter regions of Chinese cabbage genes.

\subsection{Plant Materials, Growth Conditions and Treatments}

In this study, the plants used for expression analysis were sampled from the "furui" Chinese cabbage seedlings. The seeds were soaked in water for $2 \mathrm{~h}$ then placed on moist filter paper in petri dish, and finally kept in the dark to germinate at $25^{\circ} \mathrm{C}$ for $16 \mathrm{~h}$. After germination, uniformly geminated seeds were sown in 50-hole tray filled with substrate and then put in an artificial climate chamber. The growth condition of the artificial climate chamber was as follows: photoperiod $12 \mathrm{~h} / 12 \mathrm{~h}$, temperature $25^{\circ} \mathrm{C} / 18{ }^{\circ} \mathrm{C}$ (day/night), relative humidity $80 \%$, light intensity $250 \mu \mathrm{mol} \cdot \mathrm{m}^{-2} \cdot \mathrm{s}^{-1}$. After sowing for 23 days, the uniform seedlings were selected and treated with low temperature $10{ }^{\circ} \mathrm{C} / 5^{\circ} \mathrm{C}$ (day/night), high temperature $35^{\circ} \mathrm{C} / 20^{\circ} \mathrm{C}$ (day/night), $2 \% \mathrm{NaCl}$ solution, and under natural drought conditions for $0 \mathrm{~h}, 24 \mathrm{~h}, 48 \mathrm{~h}$, and $72 \mathrm{~h}$. The leaves treated with high temperature, low temperature, salt and drought stress for $0 \mathrm{~h}, 24 \mathrm{~h}, 48 \mathrm{~h}$ and $72 \mathrm{~h}$ were sampled, which was frozen with liquid nitrogen and stored at $-80{ }^{\circ} \mathrm{C}$ for the following experiment. 


\subsection{RNA Isolation and qRT-PCR Analysis}

Total RNA was extracted from leaf tissues by using the Plant RNA Extraction Kit (Takara, Kusatsu, Japan). The first-strand cDNA fragment was synthesized from total RNA by using the Prime Script ${ }^{\circledR}$ RT Reagent kit (Takara, Kusatsu, Japan). The reverse transcripts were preserved at $20^{\circ} \mathrm{C}$ for the following PCR amplification. The CDS sequences of $B r S R O$ genes were input into the homepage of Shanghai biology company (Shanghai, China) for online primer design (as shown in Table 3), and then the primer sequences were synthesized. The actin gene was used for internal reference. The amplification system contained $2 \mu \mathrm{L}$ cDNA, upstream primers $0.6 \mu \mathrm{L}$, downstream primers $0.6 \mu \mathrm{L}$, Rox $0.4 \mu \mathrm{L}$, SYBR $10 \mu \mathrm{L}$, reaction mix $6.4 \mu \mathrm{L}$, and $\mathrm{ddH}_{2} \mathrm{O} 20 \mu \mathrm{L}$. The PCR cycling conditions included an initial polymerase activation step of $95^{\circ} \mathrm{C}$ for $15 \mathrm{~min}$, followed by 40 cycles of $95^{\circ} \mathrm{C}$ for $10 \mathrm{~s}$, and $60^{\circ} \mathrm{C}$ for $30 \mathrm{~s}$. Three biological replications for each sample were done. The relative expression levels of the $B r S R O$ gene are represented in the form of relative changes by the $2^{-\Delta \Delta C t}$ method [46]. Three biological replicates were carried out and the significance was determined with SPSS software. (SPSS 17.0, IBM, Chicago, IL, USA) $(p \leq 0.05)$

Table 3. The sequences of primers used for qRT-PCR.

\begin{tabular}{|c|c|c|}
\hline Gene Name & Forward Primer Sequence $\left(5^{\prime}-3^{\prime}\right)$ & Reverse Primer Sequence $\left(5^{\prime}-3^{\prime}\right)$ \\
\hline BrSRO01 & AAGCTGAGGATGATTGTTGGAGA & CAAAGCAGTGTGTGGTAAGCG \\
\hline BrSRO02 & GGGTTTGCCGCCGTTGGATC & TTTGCCGCCGCCTTCTTCAC \\
\hline BrSRO03 & AAGCCTGCTGAGGAGGAAGACC & CGACGCCACCTGAAAACCTATACG \\
\hline BrSRO04 & GAACTCACGGCTCACCTTGGAAG & GAGCAGAGGGTAAGGCATCAAAGC \\
\hline BrSRO05 & AGCTGCGGAGTCGGAAGATGG & CCTCGTGGAACAACCTCAGACTTC \\
\hline BrSRO06 & AATGAATGCTCGTGGTCCGTTGG & GCTTGGTGGTGGCGGTGAAG \\
\hline $\mathrm{BrSRO07}$ & GCGATCACCACGAGAGCCAAG & AGCCAGCGTACCAACCGTATTTG \\
\hline BrSRO08 & GCGGAGGCTATGAAGAGGAAGAAC & CGACCTCGCTGCTGCTAAACC \\
\hline BrSRO09 & CACCAAACCCGCAGACCCAAG & TGACCAGCGACTTCCCAGAGC \\
\hline BrSRO10 & TCTGGTGTCAAGCCTGCTGGAG & CGAGCTTCCGCAATCTCACTGG \\
\hline BrSRO11 & GCGGTTGTGTCAGTGCTGTCC & GCCACTTGTCTCATCTTCCGAACC \\
\hline BrSRO12 & GTGTGGAAGAAAGGATGCGAGGAC & CGTTGATTTGCTGCCGAACATCTG \\
\hline actin & CCAGGAATCGCTGACCGTAT & CTGTTGGAAAGTGCTGAGGGA \\
\hline
\end{tabular}

Author Contributions: Conceptualization, J.Y. and L.H.; methodology, Y.Q., X.G., Z.L. and Y.W.; software, Y.Q., X.G.; validation, Y.Q. and X.G.; formal analysis, Y.Q.; investigation, Y.Q. and X.G.; resources, Y.Q.; supervision, J.Y.; data curation, Y.Q. and L.H.; writing-original draft preparation, Y.Q.; writing-review and editing, Y.Q., X.G., Z.L., Y.W., J.Y. and L.H.; project administration, J.Y. and L.H.; funding acquisition, J.Y. and L.H. All authors have read and agreed to the published version of the manuscript.

Funding: This research was supported by National Natural Science Foundation of China (31660584), National Key R\&D Plan special plan (17ZD2NA015), Gansu Provincial Natural Science Foundation (18JR3RA166), Scientific Research Start-up Funds for Openly-Recruited Doctors (GSAU-RCZX201713) and Sheng Tongsheng Innovation Funds (GSAU-STS-2018-32).

Conflicts of Interest: The authors declare no conflict of interest.

\section{References}

1. Liu, S.; Liu, S.; Wang, M.; Wei, T.; Meng, C.; Wang, M.; Xia, G. A wheat similar to rcd-one gene enhances seedling growth and abiotic stress resistance by modulating redox homeostasis and maintaining genomic integrity. Plant Cell 2014, 26, 164-180. [CrossRef] [PubMed]

2. You, J.; Zong, W.; Du, H.; Hu, H.; Xiong, L. A special member of the rice sro family, ossro1c, mediates responses to multiple abiotic stresses through interaction with various transcription factors. Plant Mol. Biol. 2014, 84, 693-705. [CrossRef] [PubMed]

3. Jaspers, P.; Blomster, T.; Brosché, M.; Salojärvi, J.; Ahlfors, R.; Vainonen, J.P.; Reddy, R.A.; Immink, R.; Angenent, G.; Turck, F.; et al. Unequally redundant rcd1 and sro1 mediate stress and developmental responses and interact with transcription factors. Plant J. 2009, 60, 268-279. [CrossRef] [PubMed] 
4. Citarelli, M.; Teotia, S.; Lamb, R.S. Evolutionary history of the poly(adp-ribose) polymerase gene family in eukaryotes. BMC Evol. Biol. 2010, 10, 308. [CrossRef]

5. Jaspers, P.; Overmyer, K.; Wrzaczek, M.; Vainonen, J.P.; Blomster, T.; Salojärvi, J.; Reddy, R.A.; Kangasjärvi, J. The rst and parp-like domain containing sro protein family: Analysis of protein structure, function and conservation in land plants. BMC Genom. 2010, 11, 170. [CrossRef]

6. Katiyar-Agarwal, S.; Zhu, J.; Kim, K.; Agarwal, M.; Fu, X.; Huang, A.; Zhu, J.K. The plasma membrane na+/h+ antiporter sos1 interacts with rcd1 and functions in oxidative stress tolerance in Arabidopsis. Proc. Natl. Acad. Sci. USA 2006, 103, 18816-18821. [CrossRef]

7. Ahlfors, R.; Lång, S.; Overmyer, K.; Jaspers, P.; Brosché, M.; Tauriainen, A.; Kollist, H.; Tuominen, H.; Belles-Boix, E.; Piippo, M.; et al. Arabidopsis radical-induced cell death1 belongs to the wwe protein-protein interaction domain protein family and modulates abscisic acid, ethylene, and methyl jasmonate responses. Plant Cell 2004, 16, 1925-1937. [CrossRef]

8. Vainonen, J.P.; Jaspers, P.; Wrzaczek, M.; Lamminmäki, A.; Reddy, R.A.; Vaahtera, L.; Brosché, M.; Kangasjärvi, J. Rcd1-dreb2a interaction in leaf senescence and stress responses in Arabidopsis thaliana. Biochem. J. 2012, 442, 573-581. [CrossRef]

9. Teotia, S.; Lamb, R.S. The paralogous genes radical-induced cell death1 and similar to rcd one1 have partially redundant functions during Arabidopsis development. Plant Physiol. 2009, 151, 180-198. [CrossRef] [PubMed]

10. Zhao, X.; Gao, L.; Jin, P.; Cui, L. The similar to rcd-one 1 protein sro1 interacts with gpx3 and functions in plant tolerance of mercury stress. Biosci. Biotechnol. Biochem. 2018, 82, 74-80. [CrossRef]

11. Borsani, O.; Zhu, J.; Verslues, P.E.; Sunkar, R.; Zhu, J.K. Endogenous sirnas derived from a pair of natural cis-antisense transcripts regulate salt tolerance in Arabidopsis. Cell 2005, 123, 1279-1291. [CrossRef] [PubMed]

12. Li, B.Z.; Zhao, X.; Zhao, X.L.; Peng, L. Structure and function analysis of Arabidopsis thaliana sro protein family. Yi Chuan Hered. 2013, 35, 1189-1197. [CrossRef] [PubMed]

13. Li, H.; Li, R.; Qu, F.; Yao, J.; Hao, Y.; Wang, X.; You, C. Identification of the sro gene family in apples (malus $\times$ domestica) with a functional characterization of mdrcd1. Tree Genet. Genomes 2017, 13, 94. [CrossRef]

14. You, J.; Zong, W.; Li, X.; Ning, J.; Hu, H.; Li, X.; Xiao, J.; Xiong, L. The snac1-targeted gene ossro1c modulates stomatal closure and oxidative stress tolerance by regulating hydrogen peroxide in rice. J. Exp. Bot. 2013, 64, 569-583. [CrossRef]

15. Cheng, F.; Liu, S.; Wu, J.; Fang, L.; Sun, S.; Liu, B.; Li, P.; Hua, W.; Wang, X. Brad, the genetics and genomics database for brassica plants. BMC Plant Biol. 2011, 11, 136. [CrossRef]

16. Huang, X.Y.; Tao, P.; Li, B.Y.; Wang, W.H.; Yue, Z.C.; Lei, J.L.; Zhong, X.M. Genome-wide identification, classification, and analysis of heat shock transcription factor family in chinese cabbage (Brassica rapa pekinensis). Genet. Mol. Res. GMR 2015, 14, 2189-2204. [CrossRef]

17. Tao, P.; Zhong, X.; Li, B.; Wang, W.; Yue, Z.; Lei, J.; Guo, W.; Huang, X. Genome-wide identification and characterization of aquaporin genes (aqps) in chinese cabbage (Brassica rapa ssp. Pekinensis). Mol. Genet. Genom. MGG 2014, 289, 1131-1145. [CrossRef]

18. Liu, Y.; Guan, X.; Liu, S.; Yang, M.; Ren, J.; Guo, M.; Huang, Z.; Zhang, Y. Genome-wide identification and analysis of tcp transcription factors involved in the formation of leafy head in chinese cabbage. Int. J. Mol. Sci. 2018, 19, 847. [CrossRef]

19. Wang, Z.; Tang, J.; Hu, R.; Wu, P.; Hou, X.L.; Song, X.M.; Xiong, A.S. Genome-wide analysis of the r2r3-myb transcription factor genes in chinese cabbage (Brassica rapa ssp. Pekinensis) reveals their stress and hormone responsive patterns. BMC Genom. 2015, 16, 17. [CrossRef]

20. Otto, H.; Reche, P.A.; Bazan, F.; Dittmar, K.; Haag, F.; Koch-Nolte, F. In silico characterization of the family of parp-like poly(adp-ribosyl)transferases (parts). BMC Genom. 2005, 6, 139. [CrossRef]

21. Hassa, P.O.; Hottiger, M.O. The diverse biological roles of mammalian parps, a small but powerful family of poly-adp-ribose polymerases. Front. Biosci. J. Virtual Libr. 2008, 13, 3046-3082. [CrossRef] [PubMed]

22. Kim, M.Y.; Zhang, T.; Kraus, W.L. Poly(adp-ribosyl)ation by parp-1: 'Par-laying' nad+ into a nuclear signal. Genes Dev. 2005, 19, 1951-1967. [CrossRef] [PubMed]

23. Xu, G.; Guo, C.; Shan, H.; Kong, H. Divergence of duplicate genes in exon-intron structure. Proc. Natl. Acad. Sci. USA 2012, 109, 1187-1192. [CrossRef] [PubMed]

24. Roy, S.W.; Penny, D. Patterns of intron loss and gain in plants: Intron loss-dominated evolution and genome-wide comparison of o. Sativa and a. Thaliana. Mol. Biol. Evol. 2007, 24, 171-181. [CrossRef] [PubMed] 
25. Cheong, J.J.; Choi, Y.D. Methyl jasmonate as a vital substance in plants. Trends Genet. TIG 2003, 19, 409-413. [CrossRef]

26. Chini, A.; Fonseca, S.; Fernández, G.; Adie, B.; Chico, J.M.; Lorenzo, O.; García-Casado, G.; López-Vidriero, I.; Lozano, F.M.; Ponce, M.R.; et al. The jaz family of repressors is the missing link in jasmonate signalling. Nature 2007, 448, 666-671. [CrossRef]

27. Eriksson, S.; Böhlenius, H.; Moritz, T.; Nilsson, O. Ga4 is the active gibberellin in the regulation of leafy transcription and Arabidopsis floral initiation. Plant Cell 2006, 18, 2172-2181. [CrossRef]

28. Liang, W.; Ma, X.; Wan, P.; Liu, L. Plant salt-tolerance mechanism: A review. Biochem. Biophys. Res. Commun. 2018, 495, 286-291. [CrossRef]

29. Wang, Q.; Guan, C.; Wang, P.; Ma, Q.; Bao, A.K.; Zhang, J.L.; Wang, S.M. The effect of Athkt1;1 or AtSOS1 mutation on the expressions of $\mathrm{Na}^{+}$or $\mathrm{K}^{+}$transporter genes and ion homeostasis in Arabidopsis thaliana under salt stress. Int. J. Mol. Sci. 2019, 20, 1085. [CrossRef]

30. Ahuja, I.; de Vos, R.C.; Bones, A.M.; Hall, R.D. Plant molecular stress responses face climate change. Trends Plant Sci. 2010, 15, 664-674. [CrossRef]

31. TAIR. Available online: http://www.Arabidopsis.org (accessed on 11 November 2015).

32. Wang, X.; Wang, H.; Wang, J.; Sun, R.; Wu, J.; Liu, S.; Bai, Y.; Mun, J.H.; Bancroft, I.; Cheng, F.; et al. The genome of the mesopolyploid crop species brassica rapa. Nat. Genet. 2011, 43, 1035-1039. [CrossRef] [PubMed]

33. Banana Genome Hub. Available online: http://banana-genome-hub.southgreen.fr/ (accessed on 17 September 2020).

34. RGAP. Available online: http://rice.plantbiology.msu.edu (accessed on 11 November 2015).

35. Phytozome. Available online: https://phytozome.jgi.doe.gov/pz/portal.html (accessed on 17 September 2020).

36. SMART. Available online: http://smart.embl.de/ (accessed on 11 November 2015).

37. Artimo, P.; Jonnalagedda, M.; Arnold, K.; Baratin, D.; Csardi, G.; de Castro, E.; Duvaud, S.; Flegel, V.; Fortier, A.; Gasteiger, E.; et al. Expasy: Sib bioinformatics resource portal. Nucleic Acids Res. 2012, 40, W597-W603. [CrossRef] [PubMed]

38. Yu, C.S.; Lin, C.J.; Hwang, J.K. Predicting subcellular localization of proteins for gram-negative bacteria by support vector machines based on n-peptide compositions. Protein Sci. A Publ. Protein Soc. 2004, 13, 1402-1406. [CrossRef] [PubMed]

39. Kumar, S.; Stecher, G.; Tamura, K. Mega 7: Molecular evolutionary genetics analysis version 7.0 for bigger datasets. Mol. Biol. Evol. 2016, 33, 1870-1874. [CrossRef] [PubMed]

40. Saitou, N.; Nei, M. The neighbor-joining method: A new method for reconstructing phylogenetic trees. Mol. Biol. Evol. 1987, 4, 406-425.

41. Felsenstein, J. Confidence limits on phylogenies: An approach using the bootstrap. Evol. Int. J. Org. Evol. 1985, 39, 783-791. [CrossRef]

42. Bailey, T.L.; Boden, M.; Buske, F.A.; Frith, M.; Grant, C.E.; Clementi, L.; Ren, J.; Li, W.W.; Noble, W.S. Meme suite: Tools for motif discovery and searching. Nucleic Acids Res. 2009, 37, W202-W208. [CrossRef]

43. Hu, B.; Jin, J.; Guo, A.Y.; Zhang, H.; Luo, J.; Gao, G. Gsds 2.0: An upgraded gene feature visualization server. Bioinformatics (Oxford, England) 2015, 31, 1296-1297. [CrossRef]

44. Voorrips, R.E. Mapchart: Software for the graphical presentation of linkage maps and qtls. J. Hered. 2002, 93, 77-78. [CrossRef]

45. Lescot, M.; Déhais, P.; Thijs, G.; Marchal, K.; Moreau, Y.; Van de Peer, Y.; Rouzé, P.; Rombauts, S. Plantcare, a database of plant cis-acting regulatory elements and a portal to tools for in silico analysis of promoter sequences. Nucleic Acids Res. 2002, 30, 325-327. [CrossRef]

46. Livak, K.J.; Schmittgen, T.D. Analysis of relative gene expression data using real-time quantitative pcr and the 2(-delta delta c(t)) method. Methods (San Diego, CA) 2001, 25, 402-408. [CrossRef] [PubMed]

(C) 2020 by the authors. Licensee MDPI, Basel, Switzerland. This article is an open access article distributed under the terms and conditions of the Creative Commons Attribution (CC BY) license (http://creativecommons.org/licenses/by/4.0/). 